\title{
Computational Shelf-Life Dating: Complex Systems Approaches to Food Quality and Safety
}

\author{
R. C. Martins • V. V. Lopes - A. A. Vicente • \\ J. A. Teixeira
}

Received: 30 September 2007 / Accepted: 14 February 2008 / Published online: 14 March 2008

(C) Springer Science + Business Media, LLC 2008

\begin{abstract}
Shelf-life is defined as the time that a product is acceptable and meets the consumers expectations regarding food quality. It is the result of the conjunction of all services in production, distribution, and consumption. Shelf-life dating is one of the most difficult tasks in food engineering. Market pressure has lead to the implementation of shelf-life by sensory analyses, which may not reflect the full quality spectra. Moreover, traditional methods for shelf-life dating and small-scale distribution chain tests cannot reproduce in a laboratory the real conditions of storage, distribution, and consumption on food quality. Today, food engineers are facing the challenges to monitor, diagnose, and control the quality and safety of food products. The advent of nanotechnology, multivariate sensors, information systems, and complex systems will revolutionize the way we manage, distribute, and consume foods. The informed consumer demands foods, under the legal standards, at low cost, high standards of nutritional, sensory, and health benefits. To accommodate the new paradigms, we herein present a critical review of shelflife dating approaches with special emphasis in computational systems and future trends on complex systems
\end{abstract}

R. C. Martins $(\bowtie) \cdot$ A. A. Vicente · J. A Teixeira IBB-Institute for Biotechnology and Bioengineering, Centro de Engenharia Biológica, Universidade do Minho, Campus of Gualtar, 4710-057 Braga, Portugal

e-mail: rui.martins@deb.uminho.pt

\section{V. Lopes}

ISR Institute of Systems and Robotics, IST-Technical University of Lisbon,

Av. Rovisco Pais, 1049-001 Lisboa, Portugal methodologies applied to the prediction of food quality and safety.

Keywords Shelf-life dating • Complex systems • Storage and distribution

\section{Introduction}

Shelf-life dating (SLD) is a consequence of food perishability during storage and distribution (Labuza 1972). SLD can be categorized into several dating systems: (1) 'Produced by'-information on the production date, (2) 'Distribution date'-information on when the foodstuff starts its distribution, (3) 'Sell by date'-last date when foods must be sold, (4) 'high-quality period' (or 'best before') - time period during which nutritional and sensory qualities are considered as high, and (5) 'shelf-life date'-when the foods are non-consumable and removed from the store (OTA 1979; Labuza 1982; Kilkast and Subramanian 2000; Eskin and Robinson 2001; Steele 2004).

All foods are susceptible to quality and safety losses. Shelf-life should reflect the loss dynamics, not simply reducing it to the number of days foods are to be removed from the market. The new paradigm is to establish a consumer-oriented SLD system, reflecting the quality loss dynamics.

Dynamic SLD is a consequence of the internal (e.g., physical, chemical, biochemical, and microbiological contaminations) and external (e.g., climate, ecology, farming practices, storage and distribution conditions, and human interaction) mechanisms. The information needed to derive a valid shelf-life is difficult to be preestablished by laboratory assessment. Therefore, 
determination of the impact of external factors is also needed. Today, the capacity for monitoring each food product throughout the distribution chain (DC) is becoming a reality because of microelectronics, which opens opportunities for computational methods (Ledauphin et al. 2006; Martins et al. 2007a; Ledauphin et al. 2008; Roca et al. 2008; Siripatrawan and Jantawat 2008).

SLD is a difficult problem. The first approaches considered that limiting factors are mostly sensory and not much attention was paid to nutritional quality. Typical storage tests are conducted at different stress levels using sensory attributes as limiting factors. When sensory panelists perceive product deterioration, the shelf-life limit is established (Gacula 1975; IFST 1993, 1998; Marsili 2000; Kilkast 2000; Giese 2000). In many cases, the microbial growth at this limit is not even near the regulatory level, but nevertheless, the obligatory tests must be performed to guarantee large food safety margins.

Quality loss kinetics have been introduced to characterize the influence of storage and distribution. These are categorized into (1) microbiological growth, recovery, and death models (predictive microbiology [PM]), (2) physical determinations (e.g., texture and color), and (3) chemical/biochemical parameters that affect nutritional and toxicological factors. A first example of this strategy was the time-temperature-tolerance studies (TTT) (Van Arsdel 1957). TTT aimed at providing specifications, tolerances, and improvements during storage and critical points throughout the DC, providing a comprehensive data compilation on refrigerated foods (Labuza 1982). Important assessments on quality and safety loss kinetics on several foods are available and compiled in the literature (OTA 1979; Labuza and Szybist 1999; Rahman 1999; Man and Jones 2000; Kilkast and Subramanian 2000; Eskin and Robinson 2001; Steele 2004).

Time-temperature integrators (TTIs) are developed to provide a dynamic SLD (Wells and Singh 1988a). These are devices with an internal enzymatic reaction that enhances a color change indicating the cumulative time-temperature history of foods along the DC (Taukis 1989; Wells and Singh 1988b; Taukis et al. 1991; Labuza et al. 1992; Tung and Brit 1992; Wells and Singh 1997, 1998). However, a single enzymatic reaction is not representative of the quality spectrum and temperature profile across the package. TIIs are still regarded as qualitative indicators and not true dynamical SLD (Wells and Singh 1988a).

Another method of SLD is by determining the cumulative effect of heat along the DC, considering that foods have different heat loads (King et al. 1988;
Brockwell 1999; Estrada-Flores et al. 2006a, b). A different methodology of SLD is by using kinetics and temperature records from a characteristic logistics pathway to estimate quality losses. By characterizing residence times and temperatures at each DC node, it is possible to obtain by Monte Carlo simulation the quality loss statistical estimates and derive SLD on a probabilistic basis (Spiess et al. 1998). Nevertheless, satisfactory results are only obtained when residence times and temperature are controlled; otherwise, large confidence intervals are obtained (Martins et al. 2007a; Martins 2004). SLD has been also tried out by using hazard analysis statistical models, such as the Weibull function (Duyvesteyn et al. 2001; Cardelli and Labuza 2001). More recently, statistical approaches using Markov models (Ledauphin et al. 2006, 2008) and artificial neural networks used for modeling shelf-life (Siripatrawan and Jantawat 2008) have been also used to estimate the shelf-life of foods.

As food quality and safety loss are nonlinear and multivariate, these approaches fail to capture the DC dynamics. Monitoring throughout the DC is essential to obtain information for establishing a robust SLD system. Monitoring at the DC is usually conducted through random destructive sampling at discrete points, and there is still a lack of standard methodology for obtaining detailed information from the DC.

Computational methods bridge experimental and DC data with information systems. Figure 1 presents the main concepts and relationships between the experimental and computational shelf-life dating (CSLD) methodologies. Experimental methodologies include (1) experimental quality and safety characterizations, (2) constant stress level testing, (3) accelerated life testing (ALT), and (4) dynamical tests at the DC (Wells and Singh 1988a). CSLD methodologies merges (1) logistics, (2) technometrics (monitoring data interpretation and control), and (3) complex systems (CSsimulation of shelf-life), enabling the interpretation of multi-scale scenarios (Martins et al. 2007a).

Experimental and computational approaches are complimentary. Experimental methodologies are designed to provide information on quality and safety losses, which are then subjected to mathematical modeling. The information, in conjunction with available internal and external factors, is used to establish shelflife dates (Martins et al. 2007a). Experimental and theoretical computational studies show that shelf-life (food quality and safety) are multivariate CS problems (Shalizi 2001; Martins 2004) and can only be solved by computational methods (Martins et al. 2007a). In this article, we present a comprehensive review on computational methods. 
Fig. 1 Experimental and computational approaches to shelf-life dating
Experimental Approach

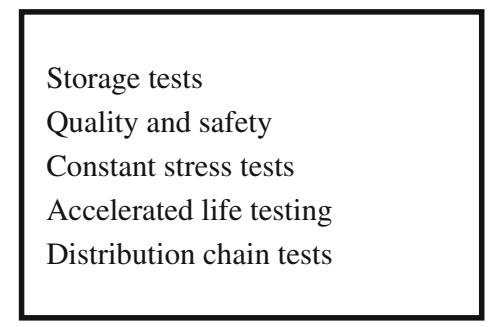

Providing knowledge on quality and safety losses to estimate shelf-life under real conditions.
Computational Approach

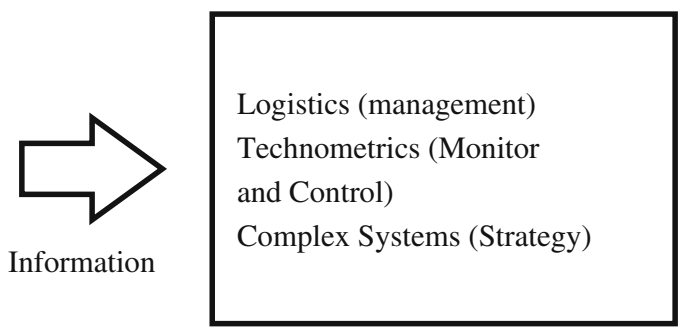

Mathematical tools to monitor, control and predict shelf-life under realistic scenario simulation environments.

\section{Shelf-Life Estimation}

Figure 2 presents the main procedures for the estimation of SLD. These include (1) identification of quality and safety parameters, (2) determining the stress variables, (3) survey of kinetic models and degradation mechanics, (4) ALT, and (5) CSLD.

Quality parameter identification is the first and most important part, because the accuracy of the dating system depends upon the monitored variables and responses (quality parameters). Several representative quality parameters should be chosen from groups: (1) microbiological, (2) physical, (3) chemical, (4) biochemical, and (5) sensory. SLD is expensive on human resources, equipment, and consumables. Therefore, it is important to assure the quality of the gathered information.

Relevant variables and responses (quality parameters) are only possible to derive using data-driven statistical analysis, and therefore, one should quantify the largest number of possible quality parameters from the different categories. A good way to start is to find relevant information on degradation mechanisms (Fennema et al. 1973; Fennema 1973; Coultate 1996; Taub and Singh 1998) and kinetic data (Labuza 1982; Jul 1984; Man and Jones 2000; Steele 2004) for each category. In many cases, it is difficult to find complete kinetic information being necessary to proceed with kinetic determinations. Therefore, the shelf-life engineer has to have a theoretical background on physicalchemical mechanisms of quality loss to select which parameters should be characterized.

After parameter selection, it is necessary to define the stress variables. Generally in SLD, the following are considered: (1) temperature, (2) water activity, (3) oxygen and antioxidant activity (oxidation management), (4) $\mathrm{pH}$, (5) ionic strength, and (6) light. In many cases, the stress variables have to be combined to determine synergistic effects, such as, in oxidation, the effects of temperature, oxygen, antioxidants, $\mathrm{pH}$, and light or even the presence of catalysts (Fennema 1973). Packaging is also another important factor to

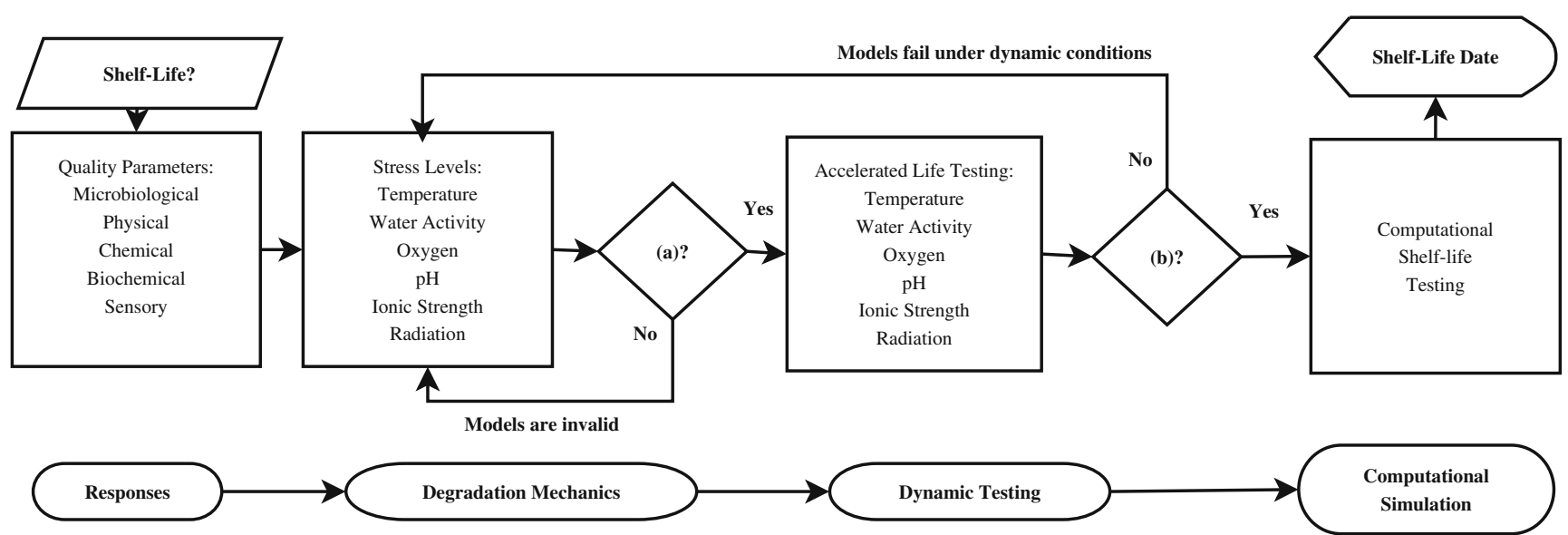

Fig. 2 Computational shelf-life dating procedures: a are constant stress level models valid?; b do models hold their theoretical assumptions under dynamic conditions? 
be taken into consideration. Packaging materials and geometrical shapes allow different levels of heat/mass transfer and light exposure, which significantly affect the rate of quality loss reactions (e.g., water and oxygen exposures). The same food will exhibit a different shelflife under different packaging materials.

\section{Constant Stress Level}

Constant stress level storage tests lie at the center of SLD (Hills and Crieger-Block 1980; Labuza 1984). In these, foods are subjected to constant storage conditions at several stress level variables to determine the deterioration mechanisms and validation of quality loss kinetics (Gacula 1975; BlackBurn 2000). Food degradation can be assumed, in general, as a reaction kinetics of order $n$ :

$\frac{\mathrm{d} C}{\mathrm{~d} t}=-k C^{n}$

where $C$ is the quality parameter concentration $\left(\mathrm{g}^{-1}\right)$, $t$ the time (s), and $k$ the kinetic rate (units depend on reaction order: $\left.C^{n-1} \mathrm{~s}^{-1}\right)$. Most of quality loss reactions tend to follow either zero, first, fractional conversion, or second order reaction kinetics, with the exception of enzyme or microbiological growth kinetics (Villota and Hawkes 1992). The zero, first, and second reaction kinetics are presented as follows, respectively:

$C=C_{0}-k t$

$C=C_{0} \cdot e^{-k t}$

$\frac{1}{C}=\frac{1}{C_{0}}+k t$

where $C_{0}$ is the initial quality. A generalized equation for reaction order greater than one can be presented as follows:

$C^{1-n}=C_{0}^{1-n}-(1-n) k t$.

Another widely used kinetics is the fractional conversion kinetics, which describes a chemical reaction until equilibrium is established (e.g., ascorbic and dihydro-ascorbic acids [AAs]):

$\frac{C-C_{\mathrm{eq}}}{C_{0}-C_{\mathrm{eq}}}=e^{-k t}$

where $C_{\text {eq }}$ is the final quality at the chemical equilibrium. Temperature is one of most important variables in food preservation. One of the first approaches for describing the temperature effect was the $Q_{10}$ concept:

$Q_{10}=\frac{k(T+10)}{k(T)}$ where $T$ is the temperature $(\mathrm{K})$ and $Q_{10}$ is the increase in $k$ given by a $10{ }^{\circ} \mathrm{C}$ increase in $T$. However, it is generally accepted that the temperature effect on most chemical reactions is well described by the Arrhenius equation:

$k=k_{0} \cdot e^{\left[-\frac{\mathrm{Ea}}{R}\left(\frac{1}{T}-\frac{1}{T_{0}}\right)\right]}$

where $k_{0}$ is the kinetic rate at $T_{0}(\mathrm{~K})$, Ea the Arrhenius activation energy $\left(\mathrm{J} \mathrm{mol}^{-1}\right)$ and $R$ the gas constant $\left(\mathrm{J} \mathrm{mol}^{-1} \mathrm{~K}^{-1}\right)$. It is possible to relate $Q_{10}$ to $\mathrm{Ea}$, by:

$\mathrm{Ea}=0.2303 R \cdot \log \left(Q_{10}\right) \cdot T(T+10)$,

which is useful for converting older data records (Labuza 1982). Reaction kinetics can also decrease because of second order phase transitions (Roos 1995). In low $a_{W}$ foods, which are either in the glassy or rubbery state, the influence of temperature is more likely to follow the William-Landel-Ferry (WLF) behavior:

$\ln (k)=\frac{-A_{1} \cdot\left(T-T_{g}\right)}{A_{2}+\left(T-T_{g}\right)}$

where $A_{1}$ and $A_{2}$ are universal constants and $T_{g}$ the invariant glass transition temperature. Under this assumption, $k$ is more sensitive near $T_{g}$ than the Arrhenius equation. In foods with limited diffusion, it is possible to relate $\mathrm{Ea}=f\left(T, T_{g}\right)$ by:

$\mathrm{Ea}=\frac{R T T_{g}}{T_{g}-T}\left[\frac{A_{1}\left(T-T_{g}\right)}{A_{2}+\left(T-T_{g}\right)}+\ln \left(k_{0}\right)\right]$,

which might be useful to be used if foods are in the rubbery state, where both WLF and Arrhenius are complementary.

PM models can complement SLD for estimating microbial growth, survival, and repair during storage (Pin et al. 1986; Foegeding 1997; Pin et al. 1997). Shelflife should not be established using limit microbiological factors, and a significant safety margin should be used to assure low risk of exceeding the contamination regulatory levels. PM models are divided in two categories: (1) primary-derived from theoretical assumptions, and (2) secondary models - which use 'black box' or hybrid models, such as artificial neural networks (Geeraerd et al. 1998; Hajmeer and Basheer 2003). Although the second approach is more practical because of the complexity of microorganisms, it is more difficult to be used in conditions different from the ones the data were collected. Primary models have the advantage of allowing to test directly the cause-effect by mathematical reasoning. Many PM growth models and data are available (Gompertz 1825; Eifert et al. 1997; Baranyi et al. 1993; Baranyi and Roberts 1995; Hills and Wright 1994; Hills and Mackey 1995; Buchanan et al. 1997; 
McKellar 1997). PM injury and repair models are extremely important for preprocessed/refrigerated foods. However, repair mechanisms are poorly understood; models such as those adopted by Hills and Wright (1994), Hills and Mackey (1995), and McKellar et al. (1997) can be used to estimate recovery. A considerable number of PM models are today available in the ComBase database (Baranyi and Tamplin 2004). More sophisticated robust PM models will only be available when the knowledge about the internal physiology and cellular communities increases. Comprehensive reviews on PM modeling can be found in Mackeller and Lu (2004) and Peleg (2006).

Kinetics determination is performed by regression analysis. The mostly used methodologies are (1) the differential method (Singh 2000), (2) the two-step procedure (Labuza and Riboh 1998), and (3) the onestep procedure (Arabshahi and Lund 1985; Cohen and Saguy 1985; Haralampu et al. 1985). The differential method increases the noise ratio, influencing the quality of regression even when using smoothing functions (Savitzky and Golay 1964). Therefore, integrated kinetic laws are always preferred. A robust methodology for determining kinetics is to divide the study into two parts: (1) Part I: using the two-step procedure to explore kinetics model candidates and (2) Part II: using the one-step approach to select and validate the final model. Nonlinear regression of kinetic models comprises deriving and solving the normal equations for each model. Derivatives can be determined analytically or numerically, and solving normal equations is performed by optimization methods such as GaussNewton, Levenberg-Marquardt, or evolutionary methods (e.g., genetic algorithms; Bates and Watts 1988; Neter et al. 1996).

In the two-step approach, the first step is used to study several kinetic models at each stress level to preselect statistically valid model candidates describing the kinetic law. Thereafter, in the second step, the estimated kinetic rates are used to study the influence of the stress variable(s) on the kinetic rate (e.g., Arrhenius or WLF; see Algorithm 1). In both steps, statistical significance of both models and parameters must be ensured. The lack of fit test and Student's $t$ analysis to kinetic parameters is sufficient at this stage to establish model candidates for the one-step procedure (Neter et al. 1996).

The one-step approach is being used to select and validate the kinetic models screened during the twostep procedure. This methodology uses all variance in data, to determine if data follows a statistically consistent kinetic pattern (Arabshahi and Lund 1985; Cohen and Saguy 1985; Haralampu et al. 1985, see

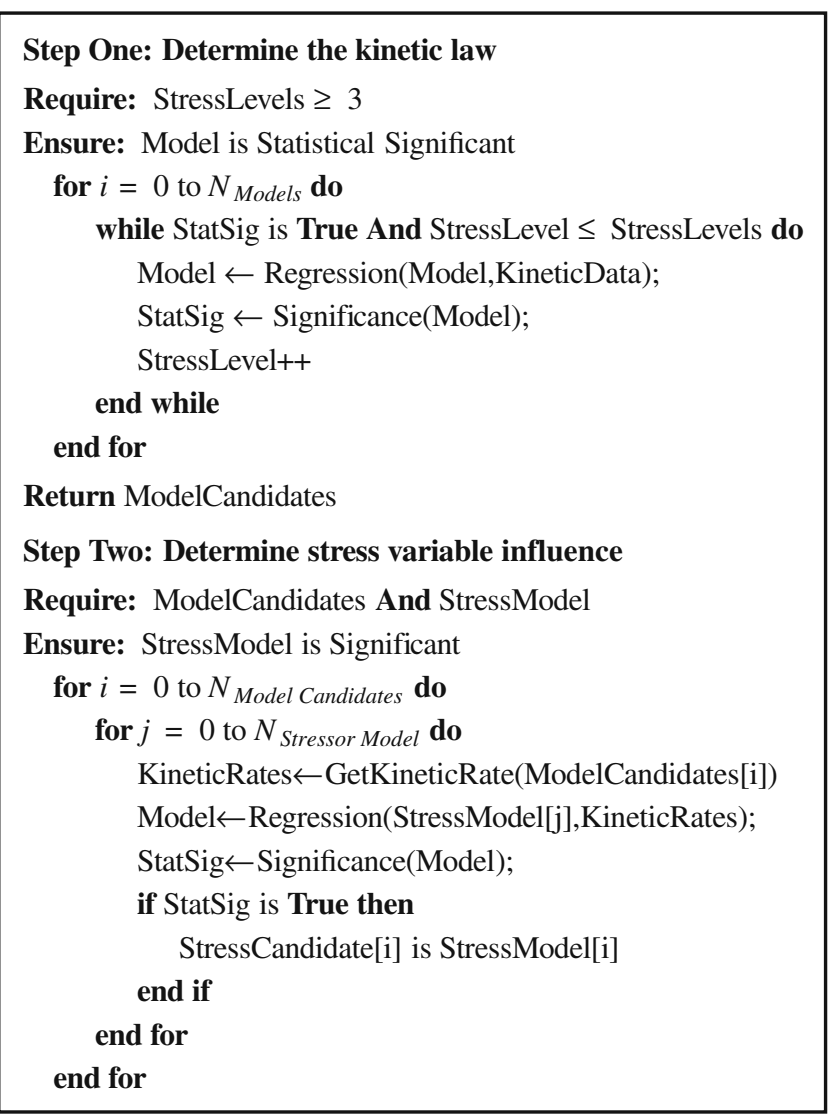

Algorithm 1 Generalised two-step procedure for kinetic models exploration

Algorithm 2). Robust regression methods use weighting functions for the residuals (e.g., Huber function [Huber 1981]), which minimizes distortions from outliers (Rousseeuw and Leroy 1987). One-step approach

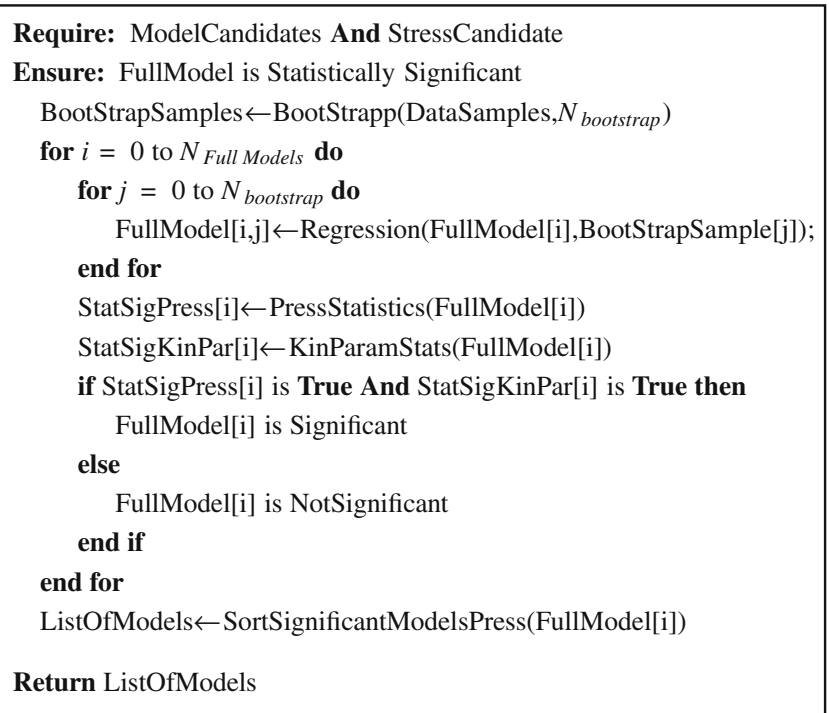

Algorithm 2 Generalised one-step procedure for kinetics determination, validation and selection 
uses also a bootstrap resampling algorithm for model validation. A large number of bootstrap samples $(n \geq$ $5,000)$ are derived from the original data to validate each one of the model candidates (Efron and Tibshirani 1993; Davinson and Hinkley 1997). For each bootstrap sample $i$, the kinetic parameters and predicted sum of squares $(P R E S S)$ are obtained by $\sum_{i=1}^{n}\left(\mathbf{Y}_{\mathbf{j}}-\hat{\mathbf{Y}}_{\mathbf{j}}\right)^{2}$, where $\mathbf{Y}_{\mathbf{j}}$ is the data leftover from the original data set after subtracting bootstrap sample $i$ and $\hat{\mathbf{Y}}_{\mathbf{j}}$ the model prediction for the $j$ sample so that it is possible to derive for each model, both PRESS and kinetic parameters statistical distributions from the original data. Valid models present significant kinetic parameters (Student's $t$ ) and the lower statistically relevant PRESS (Manly 1998).

Residuals should be studied for tendencies, outliers, randomness, and normality (Box et al. 1978). Outliers and trends give hints on experimental errors and theoretical assumptions during kinetic modeling. They should be investigated to improve the accuracy of models. For deeper information, please consult Bates and Watts (1988) and Neter et al. (1996).

In many experiments, storage conditions are not constant, such as in the refrigerators and humidity chambers. A recent study shows that temperature fluctuation inside a refrigerator can influence the accuracy of the kinetic estimates and that, during storage studies of frozen green beans, temperature fluctuation should be taken into consideration to obtain a robust kinetic determination. In these cases, one should use the two-step procedure to obtain the kinetic law estimate taking into account the time-temperature records and, thereafter, use accelerated shelf-life testing techniques to improve the kinetic estimates (Martins and Silva 2004c; Martins et al. 2004b).

\section{Accelerated Life Testing}

ALT objectives are to (1) bring down the mean time to failure (MTTF) in long storage experiments (e.g., refrigerated, frozen, dehydrated foods, fats, and oils) (Viertl 1986; Høyland and Rausand 1994), (2) test and validate kinetic mechanisms under dynamic conditions, and (3) increase the accuracy of parameter estimates by decreasing the error in the stress variable, or when a constant stress test is not practical (stage b in Fig. 2).

The majority of ALT techniques are designed only to fulfill the first criteria. These studies generally submit foods to high temperatures, water activity, oxygen, and low pHs to bring down the MTTF, which is given by critical parameters (e.g., sensory, microbiological growth, vitamin C) (Mizrahi et al. 1970; Waletzko and
Labuza 1976; Saguy et al. 1978; Labuza and Schimdl 1985). More sophisticated approaches use the two-step methodology to derive kinetic parameters with a reduced number of experiments at higher levels of stress (e.g., temperature) and, thereafter, extrapolate the kinetic rates and shelf-life for lower storage temperatures (Ragnarsson and Labuza 1977; Corradini and Peleg 2004, 2007). Nevertheless, extrapolation involves high risk of bias, and estimates are prone to systematic errors (Box et al. 1978; Bates and Watts 1988; Neter et al. 1996). To overcome this problem, linearly increasing stress tests using temperature as stress variables were developed and assessed in terms of accuracy and precision. Unsatisfactory results were obtained with $5 \%$ of error in specimen concentration, being necessary larger data sets (Rhim et al. 1989a, b; Nunes et al. 1991; Brandão and Oliveira 1997; Frias 1998).

Most of the difficulties of the ALT methodology for kinetics determinations are because of (1) lack of synchronization between sampling and temperature records, (2) large errors in the analytical method (e.g., extractions for gas chromatography or highperformance liquid chromatography analyses), and (3) error in thermocouple position (temperature representativity). Precautions that minimize these effects turn ALT into a high-output quality loss data method (Martins 2004). Under dynamic temperature conditions, quality loss is presented for the $n$ order reaction kinetics:

$C^{n}=C_{0}^{n}-(1-n) k_{0} \int_{t_{0}}^{t} e^{\left[\frac{\mathrm{Ea}}{R}\left(\frac{1}{T}-\frac{1}{T_{0}}\right)\right]} \mathrm{d} t+\int_{t_{0}}^{t} w(t) \mathrm{d} t$

where $w(t)$ is the noise function $\left(\int_{t_{0}}^{t} w(t) \mathrm{d} t=0\right.$ when $t \rightarrow \infty$, if $w(t)$ is white noise). For the first order kinetics:

$\frac{C}{C_{0}}=\exp \left[-k_{0} \int_{t_{0}}^{t} e^{\left[\frac{\mathrm{Ea}}{R}\left(\frac{1}{T}-\frac{1}{T_{0}}\right)\right]} \mathrm{d} t\right]+\int_{t_{0}}^{t} w(t) \mathrm{d} t$

where $\frac{C}{C_{0}}$ can be replaced by $\frac{C-C_{\mathrm{eq}}}{C_{0}-C_{\mathrm{eq}}}$ for the fractional conversion kinetics model under ALT conditions. Under dynamical conditions, the robust regression algorithm for determining kinetics under ALT conditions is similar to the one-step procedure, except that the stress integral $\left(\int_{0}^{t} S(t) \mathrm{d} t\right)$ has to be estimated before robust regression analysis (see Algorithm 3). The stress integral for the Arrhenius behavior is presented as follows: $\int_{t_{0}}^{t} \exp \left[\frac{\mathrm{Ea}}{R}\left(\frac{1}{T(t)}-\frac{1}{T_{0}}\right)\right] \mathrm{d} t$, whereas, if the WLF kinetics are applicable, it takes the form: $\int_{t_{0}}^{t} \exp \left[\frac{-A_{1} \cdot\left(T(t)-T_{g}\right)}{A_{2}+\left(T(t)-T_{g}\right)}\right] \mathrm{d} t$. The stress integral must be computed using the regression estimates obtained from the normal equations using the each initial estimates until convergence (Martins et al. 2004b). Validation is 


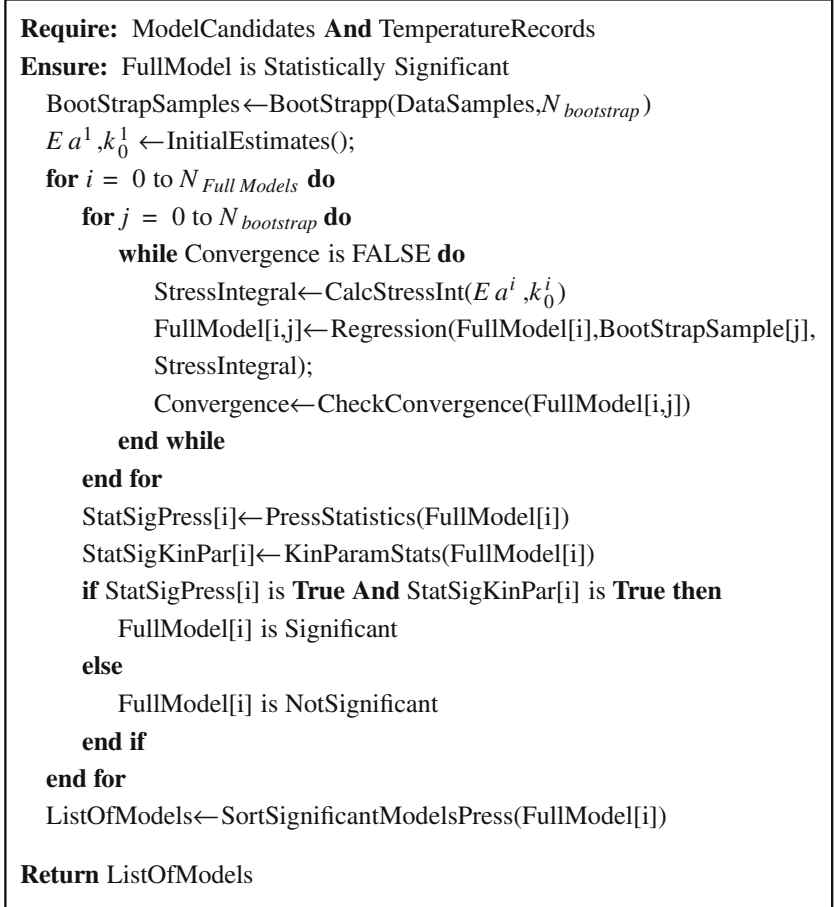

Algorithm 3 Generalised ALT procedure for kinetics determination assuming Arrhenius behaviour with temperature

also performed by bootstrap resampling to estimate the model parameters and PRESS criteria (Manly 1998).

The full potential for ALT is yet dependent upon implementation of high-output and nondestructive analytical techniques. Techniques such as spectroscopy (e.g., UV-VIS-SWNIR, infrared, and terahertz) and image analysis (e.g., hyperspectral imaging and biosensors) may aid in the direct quantification of physical, chemical, and microbiological on foods, achieving complete synchronization.

\section{Computational Shelf-Life Dating}

\section{Shelf-Life as a Complex System}

A list of properties characterizes CS: (1) elements and their number - the building blocks of a CS, (2) dynamic interactions and their strength, (3) formation/operation and their time/space-scales, (4) diversity/variability, (5) environmental conditions, and (6) activity of its parts (Yam 1997). System objects are organized into groups and hierarchies (multi-scaled), and system structures may adapt over time (Fox 1988; Fontana and Buss 1994; Shalizi 2003). CS present emergence, synergistic, and antagonistic behaviors. An emergent property is a macroscopic behavior that emerges from interactions between system objects and their intrinsic behavior, being solely explained by the integrated action of the elements (Bak 1996; Yam 1997; Hordijk 2001; Shalizi 2001).

Macroscopic models (e.g., mass/heat transfer, fluid flow) are established by mathematical reasoning and data-driven statistical analysis, ensuring a cause-effect relationship between variables and responses. Causal relationships are only observed between elementary parts. The scaling-up of these elementary relationships leads to the emergence of macroscopic structures at different scale levels (Wolfram 1994; Goles and Martinez 1997; Feldman and Crutchfield 1998; Salmon 1998). This kind of organization is observable in foods and presents significant implications for SLD because quality loss is a multi-scaled phenomenon (Martins 2004).

General precautions should be taken into consideration when building CS models, such as (1) interactions between parts must be understood at any and between scale levels: (2) do not assume that solutions are smooth in problem's domain and (3) do not assume that some elementary parts are nonrelevant. CS models represent effects into abstraction levels and bridge information between scales to model global behavior (GB).

Figure 3 exemplifies the multi-scale philosophy used for CSLD. In this approach, each level presents objects that form structures with internal behaviors. Emergence occurs at each scale level by the combination of each element and composites, being possible to control simulation from the smaller scales, such as physical (e.g., phase change, heat/mass transfer at different scales), chemical (reaction collisions under different media), biochemical (enzymatic, metabolomics, genomics, and proteomics), and microbiological (synthetic biology or PM models) phenomena. In the macroscales, factors that may need to be considered include food structures, packaging systems, transportation, warehouses, and the DC with all the necessary detail of environmental effects and human interaction (see Fig. 3). The proposed approach uses CS methodologies to organize a scenario simulation environment where food degradation is a consequence of internal mechanisms and responses to the environmental conditions observed during storage and distribution.

Human interaction is generally neglected during SLD. DC personnel and consumers behavior may lead to quality and safety losses, such as temperature abuses because of consumer behavior at the store, transportation to home and home storage. As human behavior is not controllable and it is difficult to be reproduced in the laboratory, it has not been assumed in shelf-life studies.

Agricultural transformation and distribution are collective systems, presenting a large volume of interactions between agents and system structures, forming 
Fig. 3 Food quality and safety as a CS: multi-scaled structure and dynamical relationships

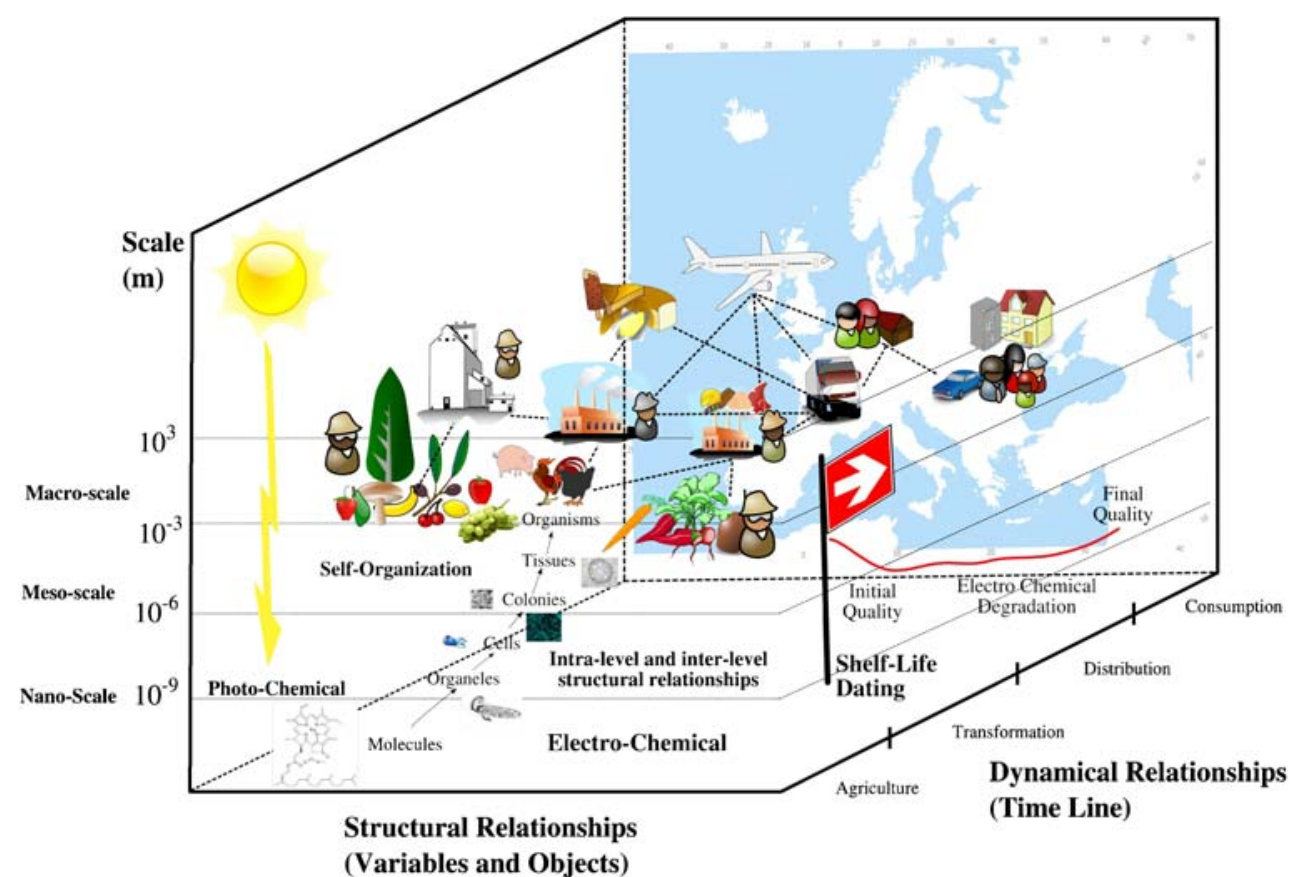

complex patterns of multi-level interactions, where ecosystems, climate, biological materials, machinery, information systems, and human behavior play an important role. The main difficulty in modeling SLD is to derive how much information is needed to describe quality losses throughout the DC. This is the subject of a new branch of modeling applied in the simulation of food and bioengineering CS (Martins et al. 2007b). A prototype computational system based on CS philosophy was developed for initiating fundamental research in this area (Martins 2004).

\section{System Architecture}

Quality and safety of foods have been modeled using the methodologies presented in "Shelf-Life Estimation." Sophisticated tools such as computational fluid dynamics (CFD) have been used for the design of equipment and process optimization (Romano et al. 2005; Zou et al. 2006; Varma and Kannan 2006; Zhang and Datta 2006; Xie et al. 2006; Hernandez and Belles 2007), with no applications in the estimation of shelflife. CFD lacks the abstraction and flexibility necessary for CSLD. Furthermore, traditional interpretation of data in CFD is visual, which is not ideal for the interpretation of large volumes of physical, chemical, and microbiological quality profiles determined by simulation. Therefore, a new tool is necessary for developing CSLD (Martins et al. 2007a). A CS simulation prototype framework was developed as a 'proof of concept' and implemented in C++ (Meyers 1998; Barton and Nackman 1991), using only open source resources (Martins 2004).

\section{Classes and Relationships}

The CSLD system was built on the multi-scale modeling and scenario technology (Cohen and Harel 2007, see Fig. 4). Simulation scenarios of elementary objects in the system are represented by finite elements (FEs). FE methods discretize physical, chemical, biochemical, and PM differential equations, which can be used to simulate most of the phenomenon that occur during food production, storage, and distribution. Fundamental levels can also use the fusion of FEs method discretizations with cellular automata (CA) (Martins 2006) and individual-based modeling for describing noncontinuous phenomena in the FE space (Martins and Lopes 2007). FE can hold many object-oriented paradigms and, by making the FE discretization independent of the PDE to be descretized on it, gives the necessary flexibility to describe physical, biochemical, and microbiological phenomena inside the elementary space. The FE multiplicity of dimensions and shape functions makes this method ideal for the use of inheritance and polymorphism between elements and shape functions (Martins 2004). Control structures at the macroscale are possible to be built from elements and elementary relationships. The assembly of the different control structures leads to the emergence of the system object libraries (e.g., transportation, warehouses, retail stores, packaging systems; see Fig. 4). The 
Fig. 4 Complex systems simulation system prototype architecture: a multi-scale class organization, b cluster/grid access, c distributed functional decomposition a

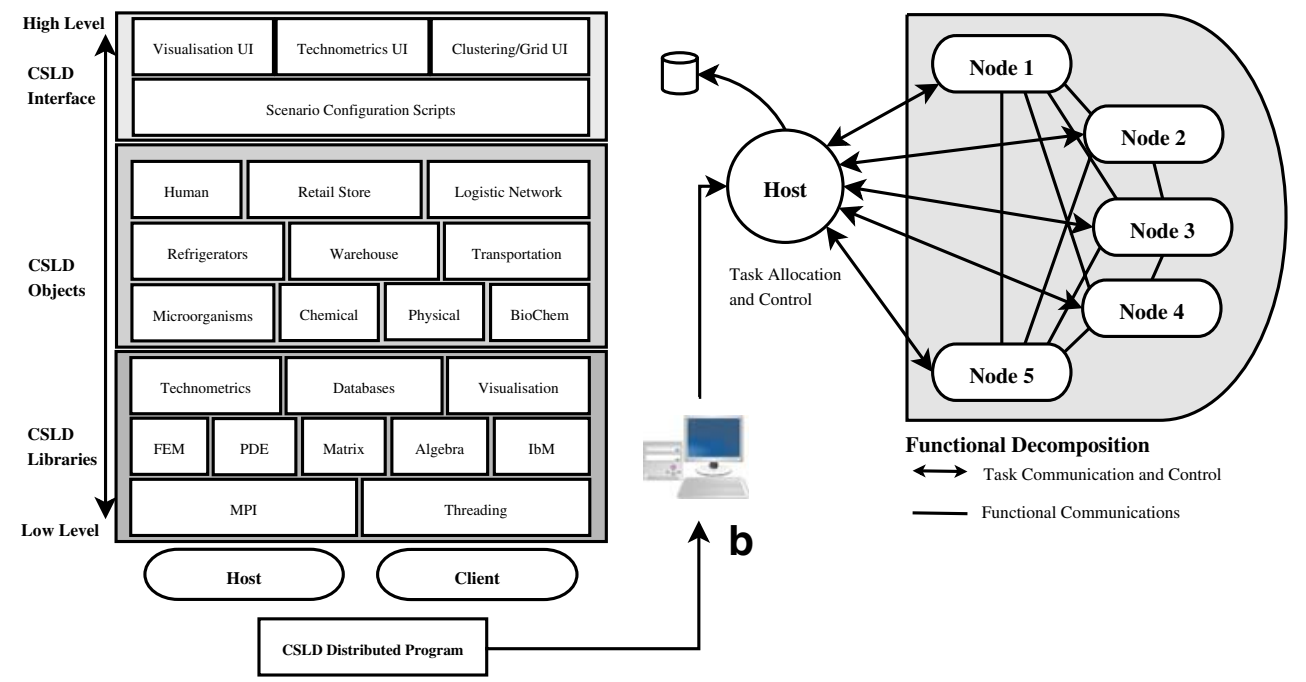

current system mode of operation resumes to the following steps: (1) scenario building using the prototype libraries at the different scale of object, that is, defining the scenarios, objects, and interactions at the different levels; (2) scenario computation and simulation-The compiled binaries (host and node programs) are allocated in the distributed system; these are controlled by the user interface configuration scripts where physical and chemical parameters are selected (e.g., kinetics, heat/mass transfer) and a scenario control script where the compiled objects can be manipulated before simulation; and (3) scenario result visualization (CFD like) and data analysis (e.g., Technometrics). The prototype system that uses third party open source libraries for matrix storage (Blitz++, Veldhuizen 2006), linear algebra (Lapack ++, Dongarra et al. 1995), and distributed code was performed using PVM (Dongarra et al. 1994).

\section{Cluster/GRID Computing: Scenario Functional Decomposition}

Distributed code was implemented using a 'scenario functional decomposition'. This is especially adequate for large-scale scenario models, where limitations in client's memory exist because of the use of commodity hardware. By using this model, communication between functional groups is minimized, maximizing the time that processors are kept busy. Buffers were also used to maintain cluster machines always executing. Figure $4 \mathrm{~b}$ summarizes how the functional decomposition was implemented. The host server is responsible for managing the tasks spawned to the client nodes, mediating the peer-to-peer communication of results between client nodes and, therefore, controlling the calculus process, which is important for load managing and scheduling of scenario simulations or under heterogeneous computational resources. The host performs the following tasks: (1) task allocation, (2) task management and calculus states of each node for mediating the peer-to-peer node relationship, (3) data storage (property databases, scenario configuration scripts, results, and mediated buffers). Host programs were designed to (1) run the client calculation program, (2) state communication to server and neighboring nodes, (3) pass results to neighboring nodes, (4) manage buffer results and send final results to the host server.

\section{Building Scenarios}

Scenario modeling is a technology currently applied to large-scale simulation systems (Harel 2001; Zeigler et al. 2002), climate and biological systems (Washington 2005; Efroni et al. 2003; Kan et al. 2004) to model GB. GB is given by interactions within the system and the environment, which specifies how objects act and interact to state changes, resulting into outwardly visible activity (Fig. 5; Jacobson 1992; Martin and Odell 1995; Beringer 1997).

Important properties define a scenario model: (1) interaction sequences (multiple possible sequences of events), (2) scenario types (states at which objects are involved), (3) scenario aggregations (subtype scenarios for the different objects, concerning their internal machinery), and (4) generalization (scenario types should be manipulated conceptually as objects, and by using hierarchy, inheritance, and polymorphism, it is possible to develop the scenario objects). Scenario technology was used as part of the concept for developing accelerated life tests (Martins and Silva 2004c; Martins et al. 2004b) and as well for determining the impact of home 


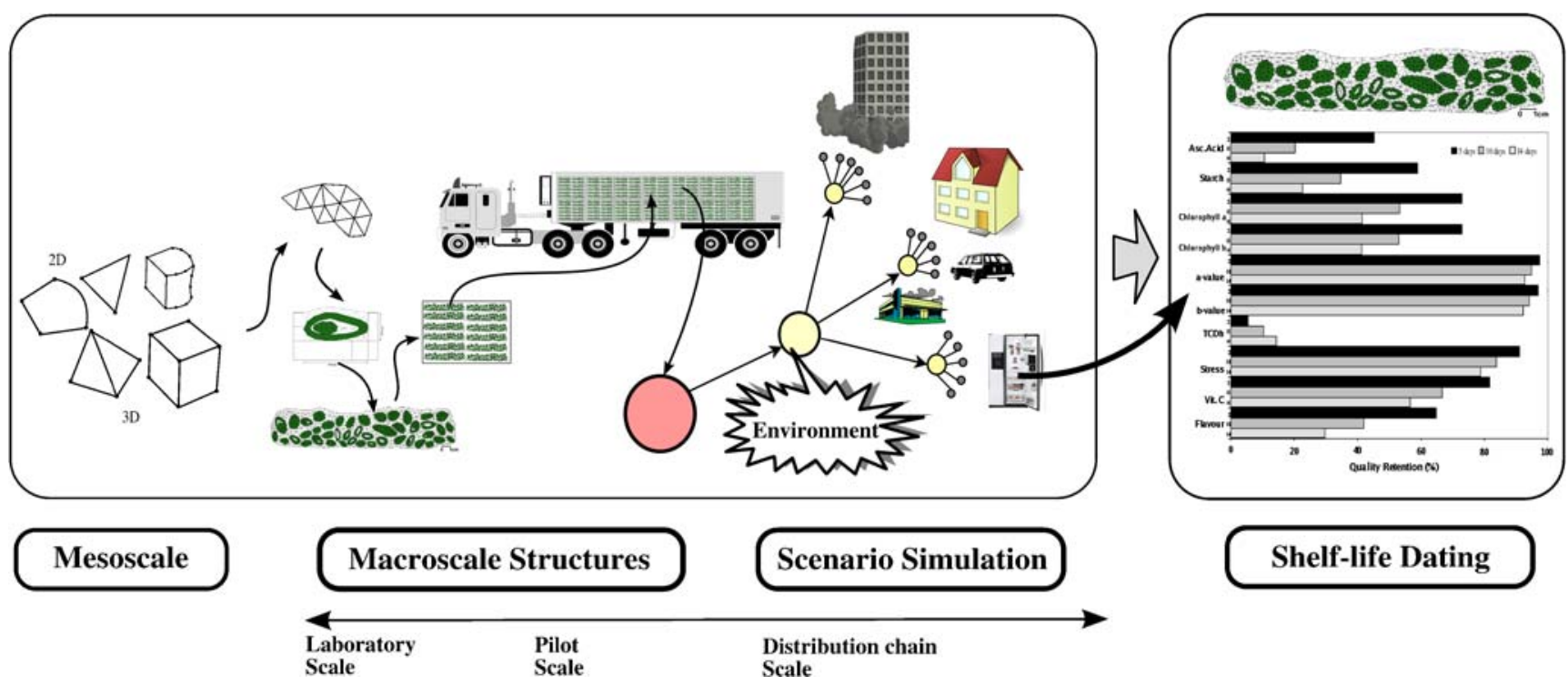

Fig. 5 Mesoscale to macroscale scenario building for shelf-life estimation: building structures from elementary levels for simulating full-scale distribution chain problems

storage in the shelf-life of frozen green beans (Martins and Silva 2004a; Martins et al. 2004a).

Mounting a scenario model is similar to any other scientific methodology. The first steps are conceptualization by object abstraction at a higher level and decomposition of the aggregated scenario objects and their relationships into functions, states, data, interactions, structures, and organization. This analysis allows building objects into much detail, as it is possible to modern scientific knowledge to simulate experiments on a computational basis.

The simple macroscale scenario for simulating frozen green beans ALT has four basic objects: (1) ALT, (2) refrigerator, (3) green bean model, and the (4) stopwatch. In this scenario, the ALT object commands the refrigerator status to increase the thermostat temperature according to the tests specifications (e.g., step stress tests, linear increase, or any other stress function), much as it is performed in a 'real world' experiment (see Fig. 6).

The refrigerator object class was developed to mimic the behavior of normal and no-frost refrigerators by using a limit cycle algorithm (Pandit and Wu 1983; Martins and Silva 2004c), being an automata that responds to the environmental temperature, door openings, thermostat position, and load. This class gives the modeler the opportunity of simulating a large number of refrigeration conditions and types of refrigerators to study their impact on food quality and shelf-life. Therefore, once the ALT object increases the thermostat position, temperature inside the refrigerator increases accordingly to its dynamics, allowing to reproduce real test conditions of heat loss and thermal cycle fluctuations that affect the surface heat transfer at the surface green bean stagnated air (see Fig. 6).

The green bean object responds dynamically to temperature fluctuations, affecting the internal chemical composition across the physical domain. Each increase in temperature accelerates the degradation process, which is calculated by an ordinary differential equation discretization of chemical reactions inside the FE space (Martins 2006). Furthermore, kinetics are highly influenced by biological variability, which can be implemented by using the stochastic FE methodologies, being possible to propagate uncertainties on physical and chemical laws across the physical domain to obtain a statistically representative solution (Martins 2006).

A simple scenario was also developed as a 'proof of concept' simulating home storage to test the validity of the star marking system. The star marking system classifies refrigerators by their operational temperature (e.g., no star $+5{ }^{\circ} \mathrm{C}, \star-6{ }^{\circ} \mathrm{C}, \star \star-12{ }^{\circ} \mathrm{C}, \star \star \star-18{ }^{\circ} \mathrm{C}$ ), and it is used to inform the consumer about the time that frozen foods should be kept inside their refrigerator according to its class. In this scenario, a green bean package object is developed with different packaging materials and stored inside different refrigerators at the recommended star marking temperatures and storage periods, respectively. Simulation results show that the packaging material is capable of affecting quality retention. Furthermore, the different quality parameters are differently affected by fluctuations of the thermal insulation. Low Ea's, such as AA auto-oxidation and starch hydrolysis, are not as significantly affected by 
a

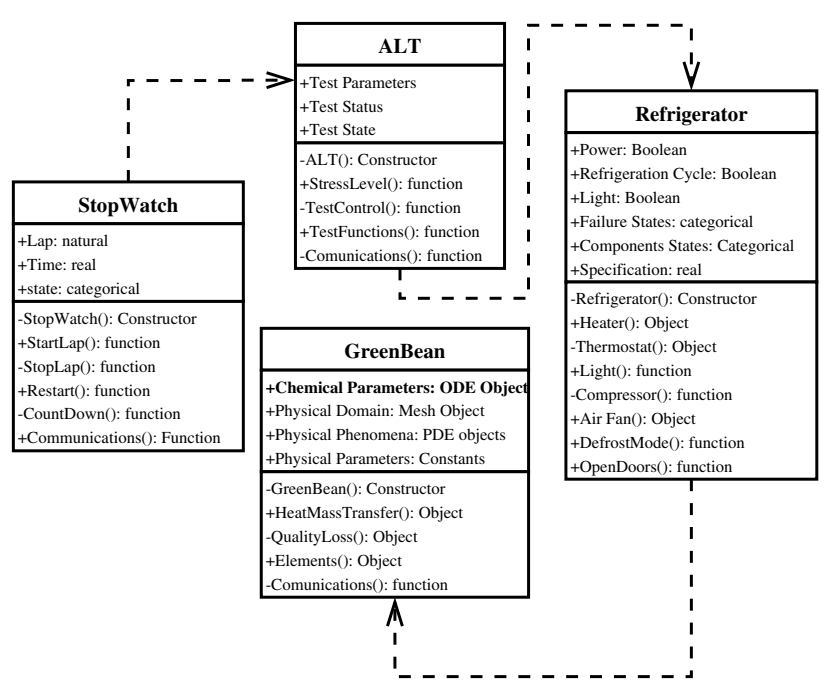

b

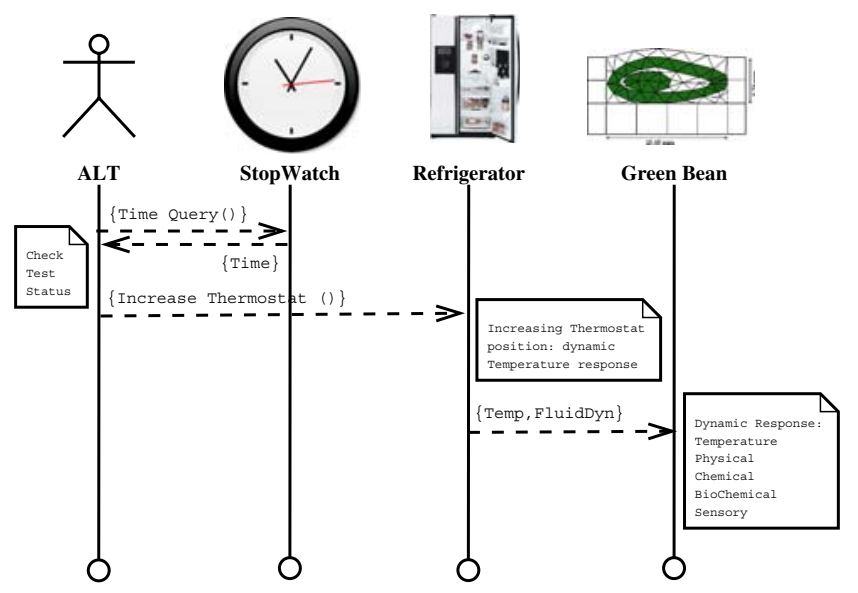

Fig. 6 Simple macroscale scenario-driven design for the simulation of accelerated life testing: a UML class relationships and b UML objects interaction diagram

the insulation material or the use of lower storage temperatures. On the contrary, sensory parameters, such as flavor and color, are highly affected by the effect of thermal fluctuations and packaging thermal insulation (Martins et al. 2004a).

Another 'proof-of-concept' scenario simulation was tested to determine quality retention during thawing at environmental and refrigeration temperatures. In this case, the scenario was mounted to determine the best conditions at which frozen green beans should be thawed before direct culinary usage (e.g., salads), to test if the 'high-temperatures short-time' (HTST) principle is applicable to thawing. A green bean package is placed on a polyethylene tray to thaw at environmental temperatures $\left(+15\right.$ to $+25^{\circ} \mathrm{C}$ simulated with auto-regressive time series models) and inside the refrigerator $\left(+3\right.$ to $\left.+7{ }^{\circ} \mathrm{C}\right)$. Simulations have shown that, during thawing, the packaging material and the environmental conditions have profound implications on quality retention. Good insulation materials have shown that thawing times can increase up to $190 \%$. Furthermore, thawing at high temperatures compromises the sensory retention, proving that the HTST principle is not applicable to thawing frozen green beans. Thawing inside the refrigerator has proven to present the best results in terms of both sensory and nutritional quality retention (Martins and Silva 2004b).

CS philosophies can also be used to help understand how emergent phenomenon occurs during food processing. A more sophisticated CS simulation was performed for understanding how nucleation occurs during supercooling of foods (Martins and Lopes 2007). In this research, a CA was developed to simulate nucleation temperatures across the physical domain of strawberries. Supercooling is a complex phenomena where water is maintained liquid below its fusion point until the nucleation temperature. Low nucleation temperatures are capable of minimizing the size of ice crystals and therefore increase the texture of frozen foods. Results have shown that, under supercooling, the nucleation temperature increases consistently toward the thermal center. This observation leads to the establishment of a CA using thermodynamic rules, which relates to the fact that ice crystals can only grow against the thermal gradient and that, after nucleation, temperature increases adiabatically locally to temperatures near the freezing point, using the enthalpy curve to estimate the nodal temperature after nucleation and the neighboring node nucleation temperature. Given these two restrictions, the CA is capable of estimating with statistical significance the different freezing conditions, from high supercoolings to quasi-equilibrium freezing conditions (Martins and Lopes 2007). CA models prove also to have a great potential to reproduce highly nonlinear physical phenomena, such as nucleation under supercooling conditions. CA are a fundamental research area that may help to solve nonlinear phenomena in foods, especially in applications that require the modelization of emergent phenomena, such as the use of micro- and nanotechnologies in foods.

The use of scenarios and CS has advantages when compared to the traditional modeling techniques 
because it allows the isolation and identification of objects, their effects and variables at each scale level. By controlling the interactions in computer models, researchers can understand at the different scale levels why quality and safety losses occur, to assist in the development of new technologies, and the strategic planning of shelf-life. Consequently, food engineers and technologists can start to understand shelf-life as a GB model under the CS philosophy and that foods can be developed in accordance to storage and distribution conditions to provide high-quality food services to consumers.

\section{Global Behavior and Shelf-Life Dating}

Simple scenarios provide the information to solve with high detail localized problems at the DC. Nevertheless, understanding GB is necessary to develop large-scale scenario simulations and systems that aid the interpretation of the generated data, so that CSLD can be a valuable strategic and operational tool for food producers and distributors. Small-scale scenario simulations can, however, provide a basis for the interpretation of GB to establish SLD.

Figure 7a presents the plot of frozen green bean quality loss parameter kinetic sensitivity to storage temperature, which form three major groups: (1) low Ea: AA, starch degradation, and texture loss; (2) intermediate Ea: total vitamin $\mathrm{C}$ and chlorophylls $\mathrm{a}$ and $\mathrm{b}$; and (3) high Ea: flavor and color retention; and Fig. 7b presents three types of DC configuration: (1) direct sales, (2) regional distribution, and (3) large-scale distribution. Given the studies performed so far with green beans, it is possible to derive a 'small world effect' (Klemm and Egulluz 2002) for the simple DC presented.
Figure $7 \mathrm{a}$ also shows that sensory quality of frozen green beans (color and flavor) can be preserved for longer periods at lower temperatures, but are sensitive to temperature fluctuations. In contrast, nutritional parameters (AA and starch) are not as sensitive to temperature, but are not being well preserved by low temperature storage. Storing or distributing green beans above the critical temperature of $-8.69^{\circ} \mathrm{C}$ leads to an accelerated quality loss, especially for color and flavor attributes. Temperature abuses are highly detrimental to the overall shelf-life, as consumers are able to detect color and flavor deteriorations.

Under direct distribution (Fig. 7b), which is the case for small production facilities, delivering to local distributors, spawning the products for a limited number of stores, Green beans that have a short pathway and limited periods of exposure to higher temperatures are expected to have high nutritional and sensory retentions and are possible to adopt a high-quality life (HQL).

Inside a state or small country (e.g., Portugal), products are delivered at a central distribution platform where loads are prepared for the different regions and stores, being transported inside refrigerated lorries. In this DC type, frozen green beans may suffer significant temperature abuses. If the refrigeration is not totally compromised, green beans are likely to retain nutritional quality but loose part of its sensory properties. Therefore, perhaps the best dating philosophy is to use the 'best before' date, inducing consumers not to use green beans before a known critical storage date, which ensures an acceptable sensory quality Best Before Date (BFD).

In a large-scale DC, such as the European market, frozen green beans are subjected to long periods of transportation and redistributions. The tempera-
Fig. 7 Emergent global pattern of shelf-life predictions: a Arrhenius plot of quality loss factors and $\mathbf{b}$ simple scale-free distribution chain networks-(1) direct sales (HQL), (2) regional distribution (BFD), (3) large scale distribution (SLD)

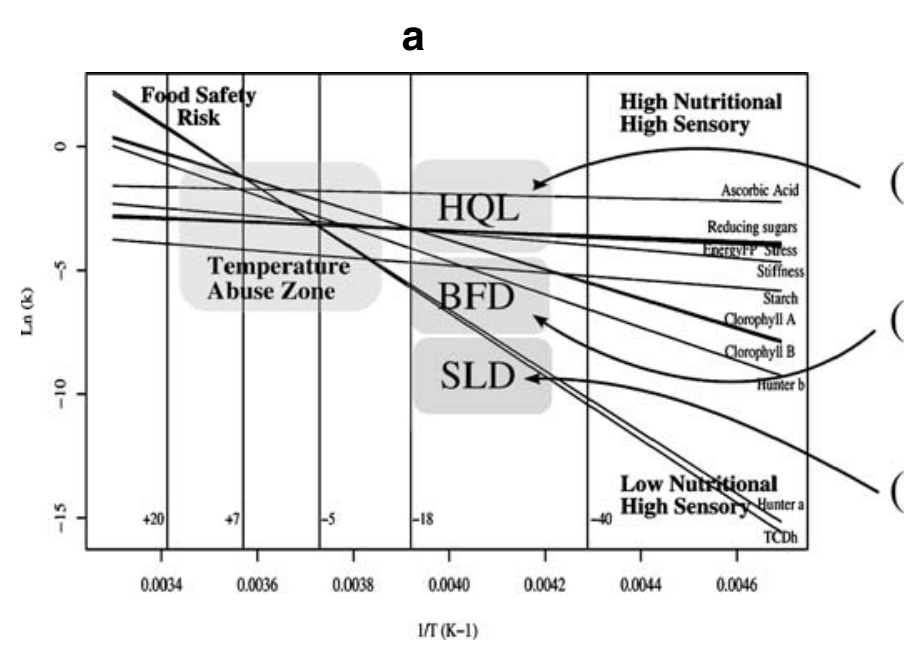

(1)

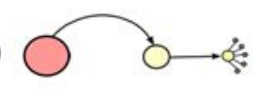

(2)

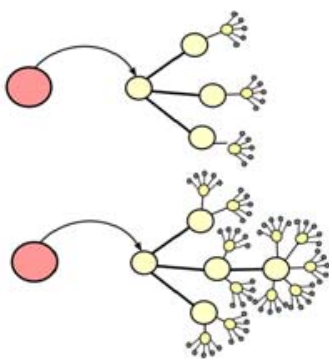


ture fluctuations, transportation, and storage time until they are available for consumption are reasonably high when compared to previous examples, making expensive to maintain both HQL or BFD dating philosophies. In this case, a more conservative philosophy should be used, reflecting on the shelf-life date when foods have to be withdrawn from the DC circuit. The SLD should reflect an equilibrium between the minimum nutritional and sensory retentions acceptable. The larger the scale of the DC, the tighter control has to be performed along the chain, so that consumers can still benefit from quality balanced frozen green beans.

\section{Conclusions}

Modeling the quality and safety of foods is a vast subject, where most factors and their interactions are still unknown. This article tries to open a new point of view on how to model food quality and safety, deriving new methodologies to study the shelf-life of foods as a consumer-oriented global problem. In the future, wholistic tools will aid food engineers to establish shelflife and manage food quality and safety in great detail. To accomplish such task, research efforts have to be put on the study of quality losses of foods, modeling of multi-scale phenomena, and fundamental research on the mathematics and computational issues of CS and scenario simulations. Under these circumstances, food quality and safety are the most important topics of CS in bioengineering, considering the increased trading of agricultural and food products in the global economy.

Acknowledgments The authors R. C. Martins (SFRH/BPD/ 26133/2005) and V. V. Lopes (SFRH/ BPD/20735/2004) gratefully acknowledge their Post-Doctoral grant to the Fundação para a Ciência e Tecnologia (FCT), and this paper is partially supported by IBB/CEB and ISR/IST plurianual funds through the POS-Conhecimento Program that includes FEDER funds.

\section{References}

Arabshahi, A., \& Lund, D. (1985). Considerations in calculating kinetic parameters from experimental data. Journal of Food Process and Engineering, 7, 239-251.

Bak, P. (1996). How nature works: The science of self-organised criticality. New York, USA: Copernicus.

Baranyi, J., \& Roberts, T. (1995). Mathematics of predictive food microbiology. International Journal of Food Microbiology, 26(2), 199-218.

Baranyi, J., \& Tamplin, M. (2004). Combase: A common database on microbial responses to food environments. Journal of Food Protection, 67(9), 1967-1971.

Baranyi, J., Roberts, T., \& McClure, P. (1993). A nonautonomous differential equation to model bacterial growth. Food Microbiology, 10, 43-59.
Barton, J., \& Nackman, L. (1991). Scientific and engineering $C++$ : An introduction with advanced techniques and examples. Reading, MA: Addison-Wesley.

Bates, D., \& Watts, D. (1988). Non-linear regression analysis and its applications. New York: Wiley.

Beringer, D. (1997). Modelling global behaviour with scenarios in object oriented analysis. PhD Thesis, Laboratoire du Génie Logiciel, LGL-DI-EPFL, Lausanne, Suisse.

BlackBurn, C. (2000). Modelling shelf-life. In D. Kilkast \& P. Subramanian (Eds.), The stability and shelf-life of food (pp. 54-78). Cambridge: CRC Press.

Box, G., Hunter, W., \& Hunter, J. (1978). Statistics for experimenters. New York: Wiley.

Brandão, T. R. S., \& Oliveira, F. A. R. (1997). The influence of the temperature increase rate on the accuracy of diffusion parameters estimate under non-isothermal conditions. International Journal of Food Science and Technology, 32, 63-72.

Brockwell, P. (1999). The export cool chain for Australian grapes and brocolli: Transport by road, sea and air. In Proceedings of the 20th international congress of refrigeration (pp. 1-6). Sydney, Australia, 19-24 September 1999.

Buchanan, R. L., Whiting, R. C., \& Damert, W. (1997). When is simple good enough: A comparison of the Gompertz, Baranyi, and three-phase linear models for fitting bacterial growth curves. Food Microbiology, 14, 313-326.

Cardelli, C., \& Labuza, T. (2001). Application of Weibull hazard analysis to the determination of shelf-life of roasted coffee. Lebensmittel Wissenshaft und Technologie, 34, 273-278.

Cohen, E., \& Saguy, I. (1985). Statistical evaluation of Arrhenius model and its applicability in prediction of food quality losses. Journal of Food Process Preservation, 9, 273-290.

Cohen, I., \& Harel, D. (2007). Explaining a complex living system: Dynamics, multi-scaling and emergence. Jounal of the Royal Society Interface, 4, 175-182.

Corradini, M., \& Peleg, M. (2004). A model of non-isothermal degradation of nutrients, pigments and enzymes. Journal of the Science of Food and Agriculture, 84, 217-226.

Corradini, M., \& Peleg, M. (2007). Shelf-life estimation from accelerated storage data. Trends in Food Science \& Technology, 18(1), 37-47.

Coultate, T. (1996). Food, the chemistry of its components. London, England: Royal Society of Chemistry.

Davinson, A., \& Hinkley, D. (1997). Bootstrap methods and their application. Cambridge: Cambridge University Press.

Dongarra, J., Geist, G., Manchek, R., \& Sunderam, V. (1994). Supporting heterogeneous network computing PVM. http:// www.epm.ornl.gov/pvm/pvm_home.htmlchem_design.ps.

Dongarra, J., Pozo, R., \& Walker, D. (1995). Lapack++. http:// math.nist.gov/lapack++.

Duyvesteyn, W. S., Shimoni, E., \& Labuza, T. (2001). Determination of the end of shelf-life for milk using Weibull hazard function. Lebensmittel Wissenshaft und Technologie, 34, 143-138.

Efron, B., \& Tibshirani, R. (1993). An introduction to the bootstrapp. Cambridge: Cambridge University Press.

Efroni, S., Harel, D., \& Cohen, I. (2003). Toward rigorous comprehension of biological complexity: Modelling, execution and visualization of thymic t-cell maturation. Genome Research, 13, 2185-2497.

Eifert, J., Hackney, C., Pierson, M., Duncan, S., \& Eigel, W. (1997). Acetic, lactic, and hydrochloric acid effects on Staphylococcus aureus $196 \mathrm{E}$ growth based on a predictive model. Journal of Food Science, 62(1), 174-178.

Eskin, M., \& Robinson, D. (2001). Shelf-life stability: Chemical, biochemical and microbiological changes. London, England: CRC Press. 
Estrada-Flores, S., Cleland, A., \& Cleland, D. (2006a). Prediction of the dynamic thermal behaviour of walls for refrigerated rooms using lumped and distributed parameter models. International Journal of Refrigeration, 24(3), 272-284.

Estrada-Flores, S., Merts, I., De Ketelaere, B., \& Lammertyn, J. (2006b). Development and validation of 'grey-box' models for refrigeration applications: A review of key concepts. International Journal of Refrigeration, 29(6), 931-946.

Feldman, D. P., \& Crutchfield, J. P. (1998). Discovering noncritical organisation: Statistical mechanical, information. Theoretical and computational views of patterns in simple one-dimensional spin systems. Journal of Statistical Physics, Santa Fe Institute Working Paper 98-04-026.

Fennema, O. (1973). Food chemistry. New York: Marcel Dekker.

Fennema, O., Powrie, W., \& Marth, E. (1973). Low-temperature preservation of foods and living matter. New York: Marcel Dekker.

Foegeding, P. (1997). Driving predictive modelling on a risk assessment path for enhanced food safety. International Journal of Food Microbiology, 36, 87-95.

Fontana, W., \& Buss, L. (1994). The arrival of the fittest: Towards a theory of biological organisation. Bulletin of Mathematical Biology, 56, 1-64.

Fox, R. (1988). Energy and evolution of life. New York: Freeman.

Frias, J. (1998). The development and application of product history indicators (PHI) for optimising product quality in drying process. PhD Thesis, Escola Superior de Biotecnologia, Universidade Católica Portuguesa, Porto, Portugal.

Gacula, M. (1975). The design of experiments for shelf-life study. Journal of Food Science, 40, 399-404.

Geeraerd, A. H., Herremans, C. H., Cenens, C., \& Vam-Impe, J. F. (1998). Application of artificial neural networks as a non-linear modular modelling technique to describe bacterial growth in chilled food products. International Journal of Food Microbiology, 44, 49-68.

Giese, J. (2000). Shelf-life testing. Food Technology, 54(7), 84-85.

Goles, E., \& Martinez, S. (1997). Cellular automata and complex systems. London, England: Kluwer.

Gompertz, B. (1825). On the nature of the function expressive of the law of human mortality, and on a new mode of determining the value of life contingencies. Philosophical Transactions of the Royal Society of London, 115, 513-583.

Hajmeer, M., \& Basheer, I. (2003). Comparison of logistic regression and neural network-based classifiers for bacterial growth. Food Microbiology, 20, 43-55.

Haralampu, S., Saguy, I., \& Karel, M. (1985). Estimation of arrhenius parameters using three least squares method. Journal of Food Process Preservation, 9, 129-143.

Harel, D. (2001). From play-in scenarios to code: And acheivable dream. Computer, 34(1), 53-60.

Hernandez, L., \& Belles, P. (2007). A 3D finite element analysis of the sunflower (Helianthus annuus) fruit. Journal of Food Engineering, 78, 861-869.

Hills, B., \& Mackey, B. (1995). Multi-compartment kinetic models for injury, resuscitation, induced lag and growth in bacterial cell populations. Food Microbiology, 12(4), 333-346.

Hills, B., \& Wright, K. (1994). A new model for bacterial growth in heterogeneous systems. Journal of Theorectical Biology, 168(1), 31-41.

Hills, C., \& Crieger-Block, R. (1980). Kinetic data generation, interpretation and use. Food Technology, 34, 56-66.

Hordijk, W. (2001). Dynamic, emergent computation in cellular automata. PhD Thesis, Albuquerque, New Mexico: University of New Mexico.

Høyland, A., \& Rausand, M. (1994). System reliability theory: Models and statistical methods. New York: Wiley.
Huber, P. (1981). Robust statistics. New York: Wiley.

IFST (1993). Shelf-life of foods: Guidelines for its determination and prediction. London, England: Institute of Food Science and Technology.

IFST (1998). Food and drink: Guidelines for its determination and prediction. London, England: Institute of Food Science and Technology.

Jacobson, I. (1992). Object-oriented engineering. Reading, MA: Addison-Wesley.

Jul, M. (1984). The quality of frozen foods. London, England: Academic.

Kan, N., Harel, D., Kugler, H., Marelley, R., Pnuelli, A., Hubbard, E. J. A., et al. (2004). Formal modelling of C. elegans development: A scenario-based approach. In G. Giobanu \& G. Rozenberg (Eds.), Modelling in molecular biology (pp. 399-417). New York: Springer.

Kilkast, D. (2000). Sensory evaluation methods for shelf-life assement. In D. Kilkast \& P. Subramanian (Eds.), The stability and shelf-life of food (pp. 79-105). Cambridge: CRC Press.

Kilkast, D., \& Subramanian, P. (2000). The stability and shelf-life of food. Cambridge: CRC Press.

King, G., Henderson, K., \& Lill, R. (1988). Shelf-life of stored aspargus is strongly related to postharvest accumulative heat units. Annals of Applied Biology, 112, 329-335.

Klemm, K., \& Egulluz, V. (2002). Growing scale-free networks with small world behaviour. Physical Review E, 65, art 057102 .

Labuza, T. P. (1972). Nutrient losses during drying and storage of dehydrated foods. Critical Reviews in Food Science, 3, 217-240.

Labuza, T. P. (1982). Shelf-life dating of foods. Wesport, CT: Food and Nutrition Press.

Labuza, T. P. (1984). Application of chemical kinetics to deterioration of foods. Journal of Chemical Education, 61(4), 348-358.

Labuza, T. P., \& Szybist, L. (1999). Current practices and regulations regarding open-dating of food products. St. Paul, MN, USA: University of Minesota.

Labuza, T. P., Fu, B., \& Taukis, P. (1992). Prediction for shelf-life and safety of minimaly processed CAP/MAP chilled foods: A review. Journal of Food Protection, 55(9), 741-750.

Labuza, T. P., \& Riboh, D. (1998). Theory and application of Arrhenius kinetics to the prediction of nutrient losses in food. Food Technology, 10, 66, 68, 70, 72, 74.

Labuza, T. P., \& Schimdl, M. K. (1985). Accelerated shelf-life testing. Food Technology, 39, 57-64, 134.

Ledauphin, S., Pommeret, D., \& Qannari, E.M. (2006). A Markovian model to study products shelf-lives. Food Quality and Preference, 17, 598-603.

Ledauphin, S., Pommeret, D., \& Qannari, E. M. (2008). Application of hidden Markov model to products shelf lives. Food Quality and Preference, 19, 156-161.

Mackeller, R., \& Lu, X. (2004). Modelling microbial responses in food. Boca Raton: CRC Press.

Man, C., \& Jones, A. (2000). Shelf-life evaluation of foods. Gaithersburg, MD: Aspen.

Manly, B. F. J. (1998). Randomization, bootstrap and Monte Carlo methods in biology. London, England: Chapman and Hall.

Marsili, R. (2000). Shelf-life prediction of processed milk by solid-phase micro-extraction, mass spectroscopy and multivariate analysis. Journal of Agricultural and Food Chemistry, 48, 3470-3475.

Martin, J., \& Odell, J. (1995). Object-oriented methods: A foundation. New Jersey: Prentice Hall. 
Martins, R. C. (2004). Modelling temperature abuses to frozen foods and effects on quality. PhD Thesis, Escola Superior de Biotecnologia, Universidade Católica Portuguesa, Porto, Portugal.

Martins, R. C. (2006). Finite volumes and finite element procedures for foods quality and safety simulations. Journal of Food Engineering, 73, 327-338.

Martins, R. C., \& Lopes, V. V. (2007). Modelling supercooling in frozen strawberries: Experimental analysis, cellular automation and inverse problem methodology. Journal of Food Engineering, 80, 126-141.

Martins, R. C., \& Silva, C. L. M. (2004a). Frozen green beans (Phaseolus vulgaris, L.) quality profile evaluation during home storage. Journal of Food Engineering, 64(4), 481-488.

Martins, R. C., \& Silva, C. L. M. (2004b). Green beans (Phaseolus vulgaris, L.) quality loss upon thawing. Journal of Food Engineering 65(1), 37-48.

Martins, R. C., \& Silva, C. L. M. (2004c). Computational design of accelerated life testing to frozen foods. Journal of Food Engineering, 64(4), 455-464.

Martins, R. C., Almeida, M. G., \& Silva, C. L. M. (2004a). Green beans (Phaseolus vulgaris, L. quality loss during home storage. Part I: Effect of storage conditions and package materials on quality retention. International Journal of Refrigeration, 27, 850-926.

Martins, R. C., Lopes, I., \& Silva, C. L. M. (2004b). Accelerated life testing of frozen green beans quality loss kinetics: Colour and starch. Journal of Food Engineering, 67(3), 339-346.

Martins, R. C., Lopes, V. V., Vicente, A. A., \& Teixeira, J. A. (2007a). Computational shelf-life dating framework: A complex systems approach for scenario-driven simulations. In Proceeding of the 1st Iberian grid infrastructure conference, scientific computing series (ISBN: 978-84-611-6634-3) (pp. 397-400).

Martins, R. C., Vicente, A. A., \& Teixeira, J. A. (2007b). Complex systems challenges in bioengineering modelling and simulation. In Proceeding of complex systems: From physics to biology and social sciences (pp. 1), Lisbon, Portugal, 22-25 November 2006.

McKellar, R. (1997). A heterogeneous population model for the analysis of bacterial growth kinetics. International Journal of Food Microbiology, 36, 179-186.

McKellar, R., Butler, G., \& Stanich, K. (1997). Modelling the influence of temperature on the recovery of Listeria monocytogenes from heat injury. Food Microbiology, 14(6), 617-625.

Meyers, S. (1998). Effective C++: 50 specific ways to improve your programs and designs. Reading, MA: Addison-Wesley.

Mizrahi, S., Labuza, T. P., \& Karel, M. (1970). Feasability of accelerated tests for browning in dehydrated cabbage. Journal of Food Science, 35, 804-807.

Neter, J., Kutner, M., Nachtsheine, C., \& Wasserman, W. (1996). Applied Linear Statistical Models, 4th edn. Chicago: IRWIN.

Nunes, R. V., Rhim, J. W., \& Swartzel, K. R. (1991). Kinetic parameter evaluation with linearly increasing temperature profiles: Integral methods. Journal of Food Science, 56, 14331437.

OTA (1979). Open shelf-life dating of foods. Washinton, DC: Office of Technology.

Pandit, S., \& Wu, S. (1983). Time series and system analysis with applications. Malabar, FL: Krieger.

Peleg, M. (2006). Advanced quantitative microbiology for foods and biosystems: Models for predicting growth and inactivation. Boca Raton: CRC Press.

Pin, C., Sutherland, J., \& Baranyi, J. (1986). Shelf-life prediction: Status and future possibilities. International Journal of Food Microbiology 33, 65-83.
Pin, C., Sutherland, J., \& Baranyi, J. (1997). Validating predictive models of food spoilage organisms. Journal of Applied Microbiology, 87, 491-499.

R-project (2007). R: A programming environment for data analysis and graphics. http://www.r-project.org.

Ragnarsson, J. O., \& Labuza, T. P. (1977). Accelerated shelflife testing for rancidity in foods-a review. Food Chemistry, 2, 291-308.

Rahman, M. (1999). Handbook of food preservation. New York: Marcel Dekker.

Rhim, J. W., Nunes, R. V., Jones, V. A., \& Swartzel, K. R. (1989a). Determination of kinetic parameters using linearly increasing temperature. Journal of Food Science, 54, 446-450.

Rhim, J. W., Nunes, R. V., Jones, V. A., \& Swartzel, K. R. (1989b). Kinetics of colour change of grape juice generated using linearly increasing temperature. Journal of Food Science, 54, 776-777.

Roca, E., Broyart, B., Guillard, V., Guilbert, S., \& Gontard, N. (2008). Predicting moisture transfer and shelf-life of multidomain food products. Journal of Food Engineering, 86(1), 74-83.

Romano, V., Marra, F., \& Tammaro, U. (2005). Modelling of microwave heating of foodstuff: Study on the influence of sample dimensions with a FEM approach. Journal of Food Engineering, 71, 233-241.

Roos, Y. (1995). Phase transition in foods. San Diego: Academic.

Rousseeuw, P., \& Leroy, A. (1987). Robust statistics and outlier detection. New York: Wiley.

Saguy, I., Mizrahi, S., Villota, R., \& Karel, M. (1978). Accelerated method for determining the kinetic model of ascorbic acid during dehydration. Journal of Food Science, 43, 1861-1964.

Salmon, J. (1998). Making an application parallel, scalable and runnable: The n-body demo. http://www.beowulf.org/ papers/nbody.ps.

Savitzky, A., \& Golay, M. J. E. (1964). Smoothing and differentiation of data by simplified least squares procedures. Analytical Chemistry, 36, 1627-1639.

Shalizi, C. (2001). Causal architecture, complexity and selforganization in time series and cellular automata. $\mathrm{PhD}$ Thesis, University of New Mexico, Albuquerque, New Mexico.

Shalizi, C. (2003). Methods and techniques of complex systems science: An overview. In T. S. Deisboek, J. Y. Kresh, \& T. B. Kepler (Eds.), Complex systems in biomedicine (pp. 33-114). London, England: Kluwer.

Singh, R. (2000). Scientific principles of shelf-life evaluation. In C. M. C. Man \& A. A. Jones (Eds.), Shelf-life evaluation of foods (pp. 3-23). Gaithersburg, MD: Aspen.

Siripatrawan, U., \& Jantawat, P. (2008). A novel method for shelf life prediction of a packaged moisture sensitive snack using multilayer perceptron neural network. Expert Systems with Applications, 34(2), 1562-1567.

Spiess, W., Boehme, T., \& Wolf, W. (1998). Quality chenges during distribution of deep frozen foods and chilled foods: Distribution chain situation and modelling considerations. In I. A. Taub \& R. P. Singh (Eds.), Food storage stability (pp. 399-417). Boca Raton: CRC Press.

Steele, M. (2004). Understanding and measuring shelf-life of food. Boca Raton: CRC Press.

Taub, J., \& Singh, R. (1998). Food storage stability. Boca Raton: CRC Press.

Taukis, P. (1989). Time-temperature indicators for shelf-life monitoring of food products. PhD Thesis, University of Minesota, St. Paul, MN.

Taukis, P., Fu, S., \& Labuza, T. P. (1991). Time temperature indicators. Food Technology, 45(10), 70-76. 
Tung, M., \& Brit, I. (1992). Food material science and food process engineering: Keys to product quality and safety. Food Research International, 8(1), 101-108.

Van Arsdel, W. B. (1957). The time tolerance of frozen foods. I. Introduction - the problem and the attack. Food Technology, 11, 28-33.

Varma, M., \& Kannan, A. (2006). CFD studies on natural convection of canned food in conical and cylindrical containers. Journal of Food Engineering, 77, 1024-1036.

Veldhuizen, T. (2006), Blitz++ user's guide. http://www. oonumerics.org/blitz/docs/blitz.pdf.

Viertl, R. (1986). Statistical methods in accelerated life testing. Göttingen: Vandenboek \& Ruprecht.

Villota, R., \& Hawkes, J. (1992). Reaction kinetics in food systems. In D. R. Heldman \& D. B. Lund (Eds.), Handbook of food engineering (pp. 39-144). New York: Marcel Dekker.

Waletzko, P., \& Labuza, T. P. (1976). Accelerated shelf-life testing of an intermediate moisture food in air and in oxygenfree atmosphere. Journal of Food Science, 41, 1338-1344.

Washington, W. (2005). The computational future for climate change research. Journal of Physics Conference Series, $16,317-324$.

Wells, J., \& Singh, R. P. (1988a). A kinetic approach to food quality prediction using full history time-temperature indicators. Journal of Food Science, 53(6), 1866-1871, 1893.
Wells, J., \& Singh, R. P. (1988b). Response characteristics of full history time-temperature indicators for perishable food handling. Journal of Food Process Preservation, 11, 207-218.

Wells, J., \& Singh, R. P. (1997). Temperature tolerance of foods during distribution. In E. Rotstein, R. P. Singh, \& K. Valentas (Eds.), Handbook of food engineering practice (pp. 405-423). Boca Raton: CRC Press.

Wells, J., \& Singh, R. (1998). Quality management during storage and distribution. In I. A. Taub \& R. P. Singh (Eds.), Food storage stability (pp. 369-386). Boca Raton: CRC Press.

Wolfram, S. (1994). Cellular automata and complexity: Collected papers. Reading, MA: Addison-Wesley.

Xie, J., Qu, X., Shi, J., \& Sun, D.-W. (2006). Effects of design on flow and temperature fields of a cold store by CFD simulation. Journal of Food Engineering, 77, 355-363.

Yam, B. (1997). Dynamics of complex systems. New York: Addison-Wesley.

Zeigler, B., Praehofer, H., \& Kim, T. (2002). Theory of modelling and simulation. San Diego: Academic.

Zhang, J., \& Datta, A. (2006). Mathematical modelling of bread baking process. Journal of Food Engineering, 75, 78-89.

Zou, Q., Opara, L., \& Mckibbin, R. (2006). A CFD modelling system for airflow and heat transfer in ventilated packaging for fresh foods: II. Computational solution, software development and model testing. Journal of Food Engineering, 77, 1048-1058. 